\title{
The relation between flower initiation and sink strength of stems and tubers of Jerusalem artichoke
}

\author{
W. J. M. MEIJER \& E. W. J. M. MATHIJSSEN \\ Centre for Agrobiological Research (CABO), P.O. Box 14, NL 6700 AA Wageningen, \\ Netherlands
}

Received 7 December 1990; accepted 19 April 1991

\begin{abstract}
In a field experiment with a late cultivar of Jerusalem artichoke (Helianthus tuberosus L.) the relation between flower initiation and the onset of redistribution of stem reserves and rapid tuber filling was studied. The treatments were designed to vary the duration of the vegetative plant stage or to alter the pattern of dry matter distribution. During the vegetative stage, tuber growth proceeds at a slow rate (about $20 \mathrm{~kg} \mathrm{ha}^{-1} \mathrm{day}^{-1}$ ) and inulin accumulates in the stems. With the plants that were kept vegetative by prolonging daylength, the tuber growth rate remained at that low level until final harvest. At the beginning of September the plants in all other treatments showed flower initiation at the apices and thereafter tuber filling rates were much higher. From the similar growth rate per tuber, with crops differing considerably in tuber number per unit area, it is concluded that total tuber growth depends on the storage capacity. Tuber number appeared to be linearly related to a cumulative temperature. The changes in relative sink strength of stems and tubers over the growth period are discussed as well as the metabolic costs and economic risks of the temporary inulin storage in the stems.
\end{abstract}

Keywords: inulin, fructan, stem reserves, carbohydrate storage, temporary sink, redistribution, Helianthus tuberosus L.

\section{Introduction}

Many plants produce fructans or inulin in their carbohydrate metabolism but only Jerusalem artichoke, chicory and dahlia accumulate these fructose polymers in their storage organs in amounts attractive for agricultural production and technological processing. Inulin can be used to make syrups rich in fructose, as a source of carbohydrate for fermentation processes, or as a source of fructose in the chemical synthesis of furan derivatives. Of that three inulin plants, most literature is devoted to Jerusalem artichoke probably because it not only has potential as an agricultural crop, but also because it appeared a suitable subject in which to study various physiological phenomena such as flower induction, tuber dormancy, the fructan metabolism and tissue differentiation. In this paper we concentrate on the process of tuber formation of Jerusalem artichoke and its constraints. The production pattern is striking, in that although the first tubers are initiated early, most of the inulin accu- 
mulates in the stems until late in the plant's life cycle. Tuber growth clearly proceeds in two phases: the first is slow and the second is fast. During the latter, tubers fill with carbohydrates from current photosynthesis and from redistribution of stem reserves (Incoll \& Neales, 1970; Barloy, 1988; Soja et al., 1989; Spitters et al., 1989). Whatever the evolutionary background of this temporary storage may be, it is unfavourable to inulin production because of the metabolic costs of redistribution and of the formation and maintenance of the extra storage tissue needed. In some climates the risks of relocation from the stems being prematurely terminated by wind damage or by early frosts must also be considered.

Chabbert et al. (1983) and Soja et al. (1989) suggest a relation between the onset of redistribution and flowering. Incoll \& Neales (1970) propose relocation to be induced by short daylength. Preliminary observations on early and late cultivars have suggested that relocation and the phase of fast tuber growth start well before flowering, possibly around the time that the transition to the reproductive state becomes visible in the apices. In the Netherlands, early cultivars make that change at the end of July and flower 4-6 weeks later. The apices of late cultivars change to reproductive between mid-August and mid-September. About 20 leaf primordia and leaves in various stages of development are then found on the apex. The lower rate of leaf appearance at the colder temperature in autumn prevent the flower buds of these late cultivars from emerging.

This paper reports on a field experiment to study the physiological relation between flower initiation and the onset of relocation of stem reserves to the tubers. The treatments were intended to advance or delay the reproductive development by planting time, forcing plants in the greenhouse and by varying daylength. A growth retardant was applied to study the influences of inhibited stem growth on the pattern of tuber growth.

\section{Methods}

In a field experiment in 1988 the cultivar Violet de Rennes was grown on fertile loamy sand. Before planting, the field was fertilized with $130 \mathrm{~kg} \mathrm{ha}^{-1} \mathrm{~N}, 100 \mathrm{~kg} \mathrm{ha}^{-1}$ $\mathrm{P}_{2} \mathrm{O}_{5}$ and $60 \mathrm{~kg} \mathrm{ha}^{-1} \mathrm{~K}_{2} \mathrm{O}$. To prevent the crop from suffering from drought, two irrigations of $20 \mathrm{~mm}$ were applied during crop establishment. During the remainder of the growing season, soil water content was high and no stress occurred. The treatments are described in Table 1.

In the long-day treatment from 30 June to final harvest the daylength in the field was extended to 18 hours by using halogen lamps suspended above the canopy that gave a light intensity of $0.5-2.0 \mathrm{~W} \mathrm{~m}^{-2}(400-700 \mathrm{~nm}, 57 \% 600-700 \mathrm{~nm})$ at plant level. A growth retardant (triapenthenol) was applied on $30 \mathrm{June}$ at $3 \mathrm{~kg} \mathrm{ha}^{-1}$ in $1000 \mathrm{l}$ $\mathrm{ha}^{-1}$ water. The transplanted crop was raised in the greenhouse at $18 / 12^{\circ} \mathrm{C}$ day/ night temperature and a 12 hour day until 4 weeks after emergence. At transplanting, stem length was about $0.4 \mathrm{~m}$.

The crops were harvested on 4 dates, timed to coincide with certain stages of crop development: two harvests were during the slow tuber filling phase in the vegetative stage and two were during the reproductive phase. 
Table 1. Experimental details of the treatments.

\begin{tabular}{lcc}
\hline Treatment & Planting date/location & Emergence \\
& & \\
Control & 13 April/field & 9 May \\
Long day (day length extended to 18 hours) & $13 \mathrm{April} /$ field & $9 \mathrm{May}$ \\
Growth retardant $\left(3 \mathrm{~kg} \mathrm{ha}^{-1}\right.$ triapenthenol, $\left.30 \mathrm{June}\right)$ & $13 \mathrm{April} /$ field & $9 \mathrm{May}$ \\
Transplanted (transplanted to the field, $12 \mathrm{May})$ & $9 \mathrm{April} / \mathrm{greenhouse}$ & $17 \mathrm{April}$ \\
Late planted & $31 \mathrm{May} / \mathrm{field}$ & $14 \mathrm{June}$ \\
\hline
\end{tabular}

The experiment was laid out as a split-plot, with the treatments as the main plots and the harvest dates as sub-plots, and was replicated four times. The tubers were planted in rows $0.75 \mathrm{~m}$ apart at a plant density of $3.8 \mathrm{~m}^{-2}$. The plots were $9 \times 3 \mathrm{~m}$; the centre $4.5 \times 1.5 \mathrm{~m}$ of each plot was harvested.

Plant stage was determined by dissecting 5 apices per replicate of main stems from border rows every week. During the vegetative stage the apex is triangular and flat or concave. At the transition to the reproductive stage it becomes circular, convex and some days later is surrounded by 6 or more primordia of equal size. The latter stage was scored as reproductive. At each harvest the dry weights of leaves, stems and tubers and the green leaf area and number of tubers were determined. Tuber growth is defined as the increase in dry weight of tubers per area. Tubers were considered as initiated if they had attained at least twice the diameter of the stolon and from that size they were included in the countings. The sugar content of the tubers and stems was determined as total reducing sugars after hydrolysis. The cumulative temperature was calculated by multiplying the numbers of days since emergence by the mean of daily minimum and maximum temperatures.

\section{Results}

The apices of the control plants changed to the reproductive state around 6 September (day number 250, Figure 1). Extending the daylength in the field to 18 hours kept about half of the plants in each plot in the vegetative phase until the final harvest. Because the light intensity was apparently marginal for daylength extension and because of mutual shading, the other half became reproductive a few days after the controls. At the third and the final harvests these reproductive plants were omitted and thus the data on the long-day treatment in this paper refer to the vegetative plants only. Statistical evaluation of the results was not hampered by this reduction of plant number per plot because for all measurements the variation of residual mean squares of the long-day treatment appeared to be within the range found with the other treatments.

Advancing the growth of the plants by raising them in a heated greenhouse at short daylength had no effect on the date of flower initiation, neither did the application of the growth retardant. Planting almost 2 months later resulted in only a few days delay (Figure 1).

In the period between the first and second harvests, tuber growth proceeded at a 


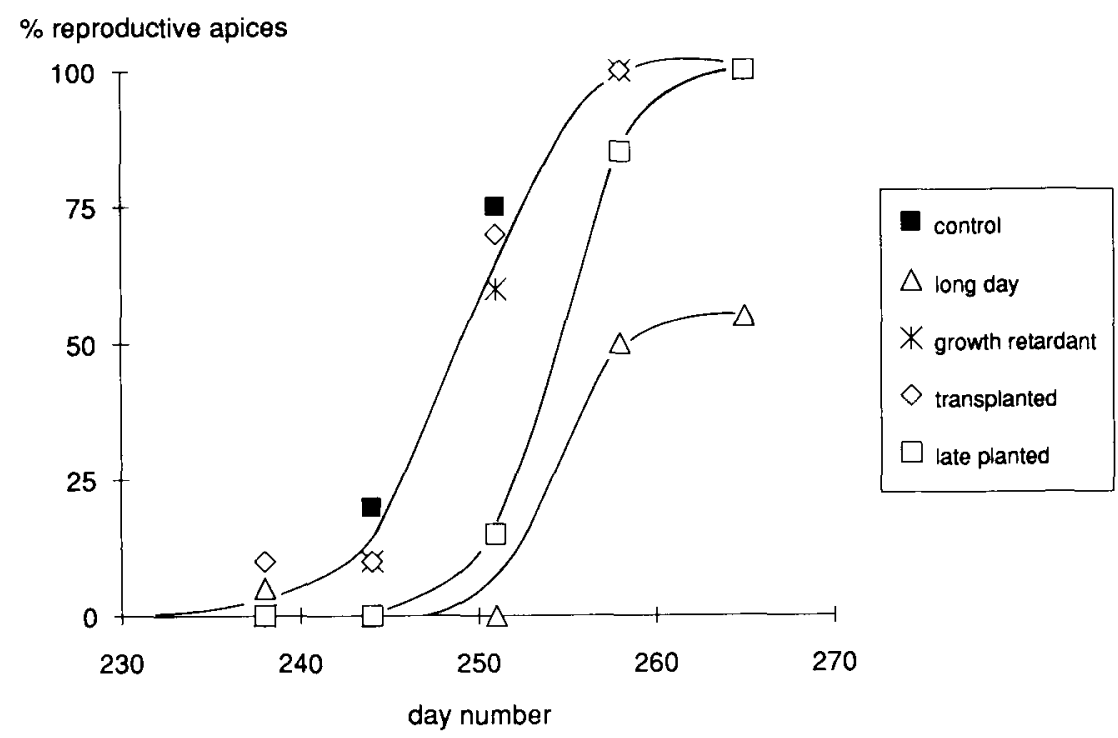

Fig. 1. The transition from the vegetative to the reproductive state of the apices of the main stem. About half of the long-day plants remained vegetative until the final harvest at day 313 .

very slow rate, about $20 \mathrm{~kg} \mathrm{ha}^{-1} \mathrm{day}^{-1}$, in all treatments and with vegetative plants (Table 2, Figure 2). Compared with the other treatments, the tuber growth rate of the crop treated with retardant was significantly faster and that of the late planting was significantly slower. From the third to the fourth harvests, only the tubers of the vegetative long-day plants grew at this slow rate. In all other treatments the plants became reproductive between the second and third harvests and these crops simultaneously changed to the fast growth phase with much increased tuber growth rates (Table 2). In Figure 2 the change-over from the first, slow tuber growth phase to the second, fast phase is indicated by broken lines. If a relation with reproductive development is assumed, then in reality that shift will proceed gradually because of

Table 2. Rates of tuber dry matter growth $\left(\mathrm{kg} \mathrm{ha}^{-1} \mathrm{day}^{-1}\right)$ and growth per tuber (mg day $\left.{ }^{-1}\right)$ in the first (slow) and second (rapid) tuber growth phases for the five crop treatments in the experiment.

$\begin{array}{llllll}\text { Control } & \text { Long } & \begin{array}{l}\text { Growth } \\ \text { day }\end{array} & \begin{array}{l}\text { Trans- } \\ \text { retardant }\end{array} & \begin{array}{l}\text { Late } \\ \text { planted }\end{array} & \begin{array}{l}\text { LSD } \\ (5 \%)\end{array}\end{array}$

Tuber growth

First phase

Second phase

15

55

Growth per tuber

First phase

Second phase

22
21

35
109

15

19
18

101

23

77

21

103

5

48

9

33 


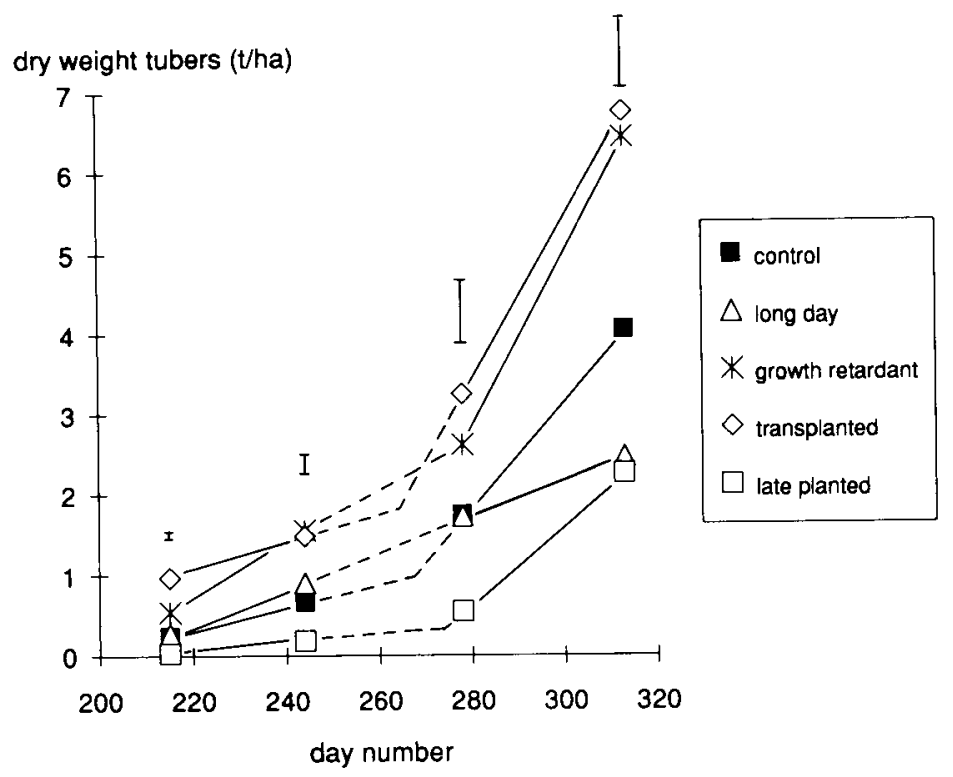

Fig. 2. Tuber dry matter yields at four harvest dates. The change-over from the first slow tuber growth phase to the second fast phase is indicated by broken lines. Vertical bars are $L S D$ at $P=0.05$.

the variation in transition time between plants (Figure 1) and probably also because it took 1 to 2 weeks for all the apices of the lateral branches to become reproductive.

From the first harvest onwards the tuber yields of the transplanted crop and of the crop treated with growth retardant were higher than the control crop, whereas those of the late planting were lower (Figure 2). The long-day crop never entered the fast growth stage and therefore had a significantly lower yield at final harvest (differences significant at $P=0.05$ ).

The first tuber initiation was observed in about mid-June in the transplanted crop and in early July for the other early plantings. At the first harvest on 2 August the transplanted crop and the crop treated with growth retardant already had many more tubers per plant and per $\mathrm{m}^{2}$ in comparison with the control crop and with the long-day crop. The late planting lagged behind (Figure 3a). Tuber number increased until the final harvest and appeared to be linearly related to the cumulative temperature (Figure $3 b$ ). The growth retardant crop is the exception in Figure $3 b$, apparently because that chemical treatment increased the tuber number considerably above the temperature-related level.

The average tuber weight was calculated from tuber yields and numbers of tubers. Average growth per tuber showed a pattern similar to total tuber production: a slow growth rate in the vegetative plants and a much higher growth rate in the reproductive plants (Figure 4, Table 2). In the first phase the growth rate per tuber was similar in all vegetative crops. As for tuber yield, until final harvest the tubers of the vegetative long-day plants remained growing at the slow rate, whereas the reproductive crops showed much faster growth rates per tuber. Tuber growth and 

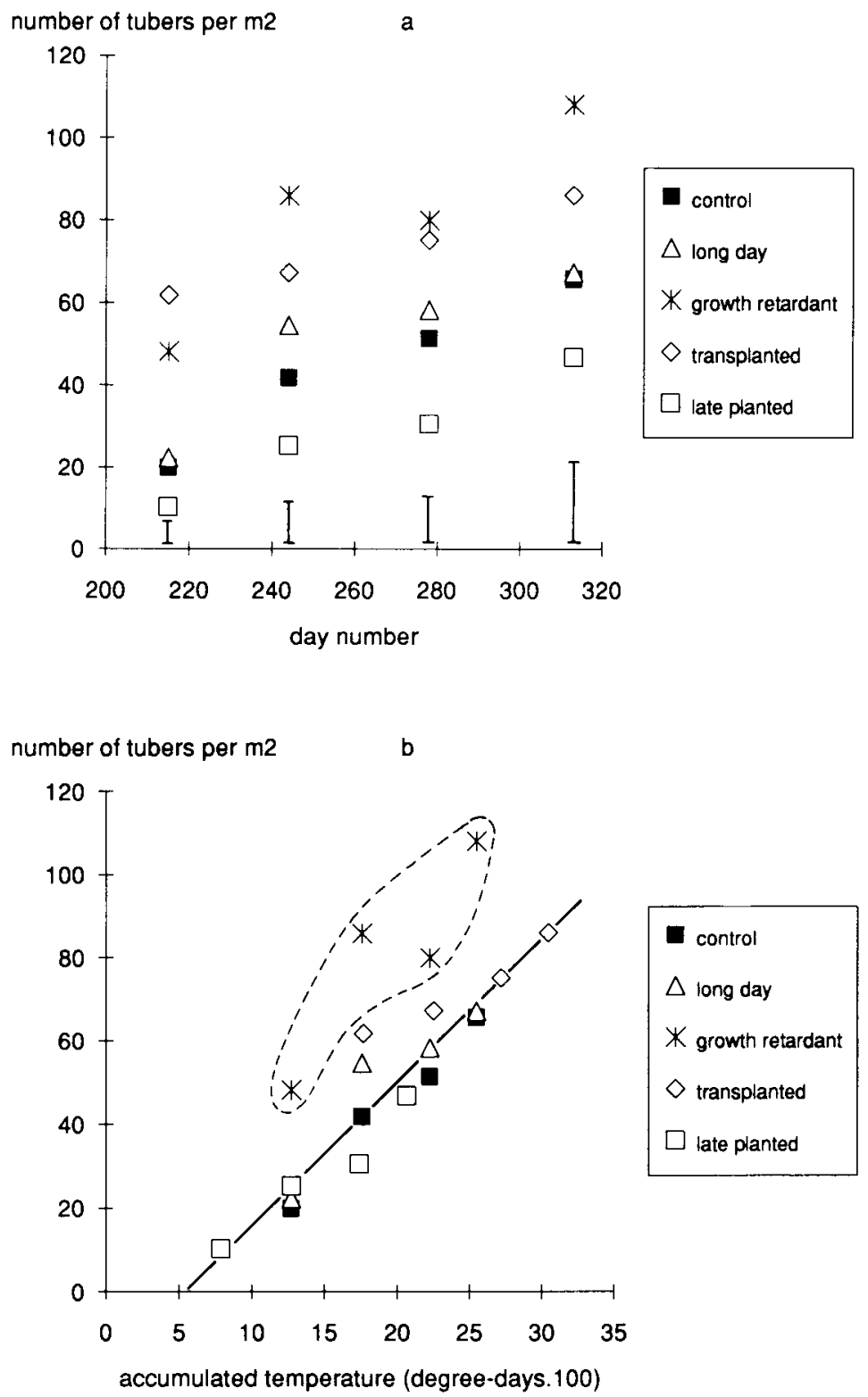

Fig. 3. Tuber number per $\mathrm{m}^{2}$ : (a) plotted against day number; (b) as a function of the accumulated temperature from emergence; $y=0.034 x-17(r=0.94)$. The data of the retardant-treated crop are not included in the calculation of the regression line. 


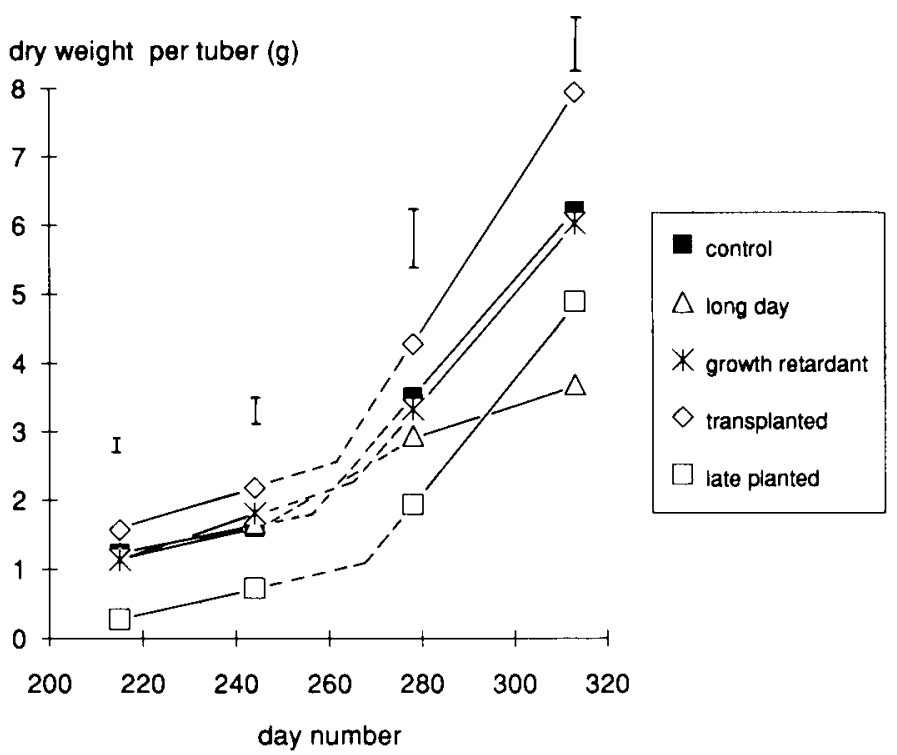

Fig. 4. Mean tuber dry weight at four harvest dates. Vertical bars are $L S D$ at $P=0.05$.

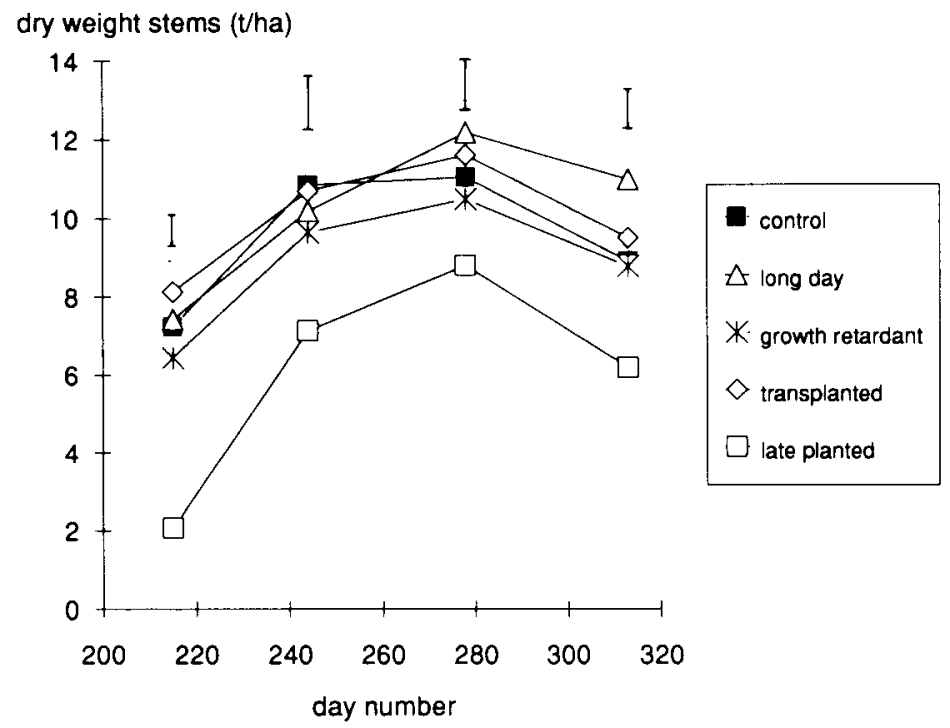

Fig. 5. Dry weight of the stems at four harvest dates. Vertical bars are $L S D$ at $P=0.05$. 
growth per tuber were not related to a cumulative temperature, unlike tuber number.

In all treatments the stem dry weight increased until the third harvest on 4 October (Figure 5). Between the third and the final harvests the stems of the reproductive crops lost $2140 \mathrm{~kg} \mathrm{ha}^{-1}$ on average, whereas the vegetative long-day plants lost only $1190 \mathrm{~kg} \mathrm{ha}^{-1}$. At final harvest, therefore, the stem weight of the vegetative crop was highest. The growth retardant tended to reduce stem weight over most of the growth period. The stem weight of the late crop was much lower at all harvests.

Some of these changes in stem weight are related to storage and redistribution of inulin. During the vegetative phase much larger amounts of sugars are stored in the stems than in the tubers (Figure 6). In the reproductive phase the decrease in the

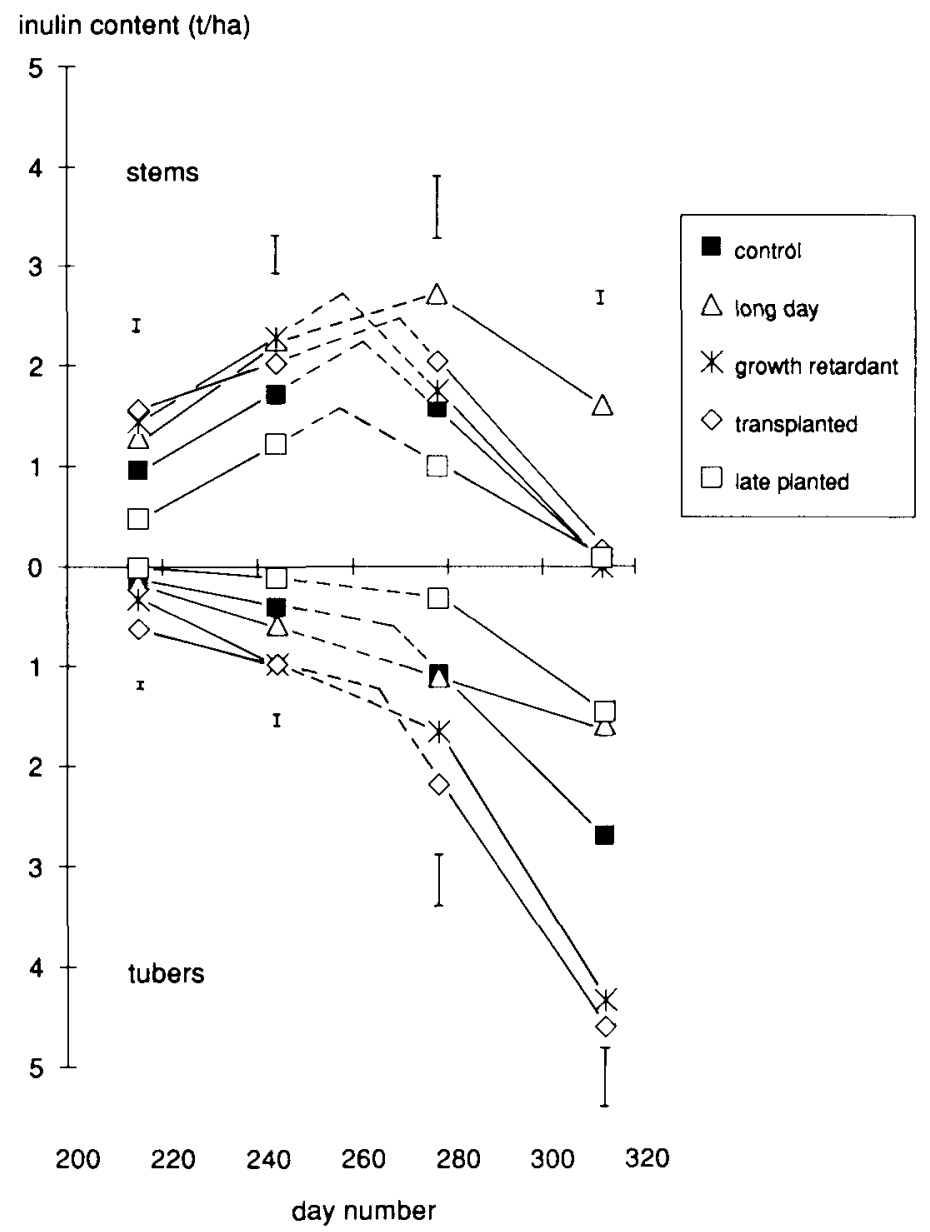

Fig. 6. Total sugar content of the stems and tubers at four harvest dates. Vertical bars are $L S D$ at $P=$ 0.05 . 
Table 3. Dry matter production and partitioning to stems, leaves and tubers (in $\mathrm{kg} \mathrm{ha}^{-1}$ ) for the five crop treatments at final harvest.

\begin{tabular}{lrllll}
\hline Crop treatment & Stems & $\begin{array}{l}\text { Total } \\
\text { leaves }\end{array}$ & Tubers & $\begin{array}{l}\text { Total dry } \\
\text { weight }\end{array}$ & $\%$ tubers \\
Control & 8920 & 2720 & 4050 & 15690 & 26 \\
Long day & 10990 & 2750 & 2460 & 16200 & 16 \\
Growth retardant & 8780 & 2850 & 6440 & 18070 & 36 \\
Transplanted & 9510 & 2360 & 6760 & 18630 & 36 \\
Late planted & 6190 & 2430 & 2250 & 10870 & 20 \\
\hline
\end{tabular}

inulin content of the stems occurs synchronously with a rapid increase in the tubers. During this rapid tuber growth stage, sugar accumulation in the tubers of the reproductive plants exceeded the decrease in the stems. As well as relocation, therefore, current photosynthesis also contributed to tuber growth. However, sugar accumulated in the tubers of the long-day plants at the same slow rate from the first to final harvest. Losses seem to have occurred in these long-day plants: the stems lost 1100 $\mathrm{kg} \mathrm{ha}^{-1}$ sugars, whereas only $500 \mathrm{~kg} \mathrm{ha}^{-1}$ accumulated in the tubers. At the final harvest, the stems of the vegetative long-day plants still contained $1600 \mathrm{~kg} \mathrm{ha}^{-1}$ sugars.

At the final harvest, considerable differences between the treatments were found in total dry matter production (Table 3). The transplanted crop and the crop treated with growth retardant produced more than the control, whereas the late crop produced less. In the control crop, $26 \%$ of total dry matter was partitioned to the tubers, against $36 \%$ for the transplanted crop and the crop treated with growth retardant. The late and the long-day crops distributed a much smaller proportion of dry matter to the tubers.

\section{Discussion}

Various authors have reported that flowering in Jerusalem artichoke is induced by a period of short days (Hackbarth, 1937; Steinrücken, 1984). Under natural daylength in our experiment all plants of the late cultivar Violet de Rennes became reproductive at the beginning of September. The short day/high temperature treatment in the greenhouse had no effect on time of flower initiation of the transplants, probably because the short days were applied while the plants were still in the photoperiodically insensitive juvenile stage or because the number of inductive cycles were inadequate. The treatment was based on the minimal induction period as found by Steinrücken (1984, p. 51-82). We took the possible risks of relying on a short induction period into account and anticipated that growth would be severely retarded if older and bigger plants were transplanted. But obviously the plants were not yet induced during the forcing in the greenhouse and the strong effects of this treatment must be related to the higher greenhouse temperature only. The higher temperatures and the emergence three weeks earlier resulted in $31 \%$ more tubers and a $67 \%$ higher tuber yield compared with the control plants. 
Tuber initiation in Jerusalem artichoke has been related to induction by short days (Hammer \& Long, 1939; Dickerson \& Edelman, 1966), to long-day influences and low temperatures during the night (Courduroux, 1967). In our experiment daylength effects on tuber initiation and tuber number are unlikely. Short-day induction can practically be precluded because the late-planted crop emerged mid-June and initiated its first tubers mid-July during the period with longest days. A longday influence is unlikely because the long-day treatment did not affect tuber numbers (Figure 3a). Barloy \& Poulain (1988) and Spitters et al. (1989) found that all cultivars in their experiments initiated their first tubers at about the same time. The latter authors suggested a certain cumulative temperature for first initiation. Jefferies \& MacKerron (1987) have also shown that the onset of tuber initiation in certain potato cultivars can be defined in terms of cumulative thermal time. Extrapolation of the linear relation between tuber number and accumulated temperature in Figure $3 \mathrm{~b}$ suggests tuber initiation to begin at 520 degree days. According to Chabbert (1983) and Spitters et al. (1989), in Jerusalem artichoke, tuber numbers will increase only until the onset of the period of fast tuber growth. Their data, however, seem not conclusive and in our experiment, tuber initiation continued until final harvest and for most treatments and all harvest dates could be described by the same linear function of the cumulative temperature. This relationship with thermal time apparently reflects the major influence of temperature on tuber initiation. Only the crop treated with growth retardant produced many more tubers, probably because the retardant specifically inhibits stolon growth and enhances tuber initiation.

For both the first phase of slow tuber growth and the second rapid phase there were significant differences between treatments in the rate of tuber growth per unit area (Table 2). In contrast, the growth per tuber in both periods appeared to be remarkably constant, although the treatments differed considerably in the number of tubers per unit area. In the second period the growth per tuber remained at the low level of the first period in the vegetative long-day plants only. The similarity in the growth rate per tuber in crops that differed considerably in tuber number per unit area suggests that tuber growth per unit area depends not on assimilate availability but is related to the storage capacity i.e. to the number of tubers or the number of storage cells, and can be characterized as sink-limited. Spitters et al. (1989) suggest sink limitation for tuber growth because of a supposed linear relation between tuber growth and temperature sum. In our experiment the tuber numbers, but not tuber growth, were linearly related to a cumulative temperature. In late autumn the situation will be different: after the stems have been exhausted, tuber growth will certainly be limited by the decreasing assimilate supply from current photosynthesis.

Jerusalem artichoke invests a relatively large part of the dry matter in the stems (Table 3). In this late cultivar the stem weight increased until the third harvest at 4 October and much of that growth was structural stem material. For instance, during August stem weight increased by about $3000 \mathrm{~kg} \mathrm{ha}^{-1}$ in all crops, and less than 1000 $\mathrm{kg} \mathrm{ha}^{-1}$ was storage of inulin (Figures 5 and 6). Application of the growth retardant tended to reduce stem growth and boosted tuber yield (Figure 5 and Table 3 ). Using a similar triazole retardant, Balamani \& Poovaiah (1985) also achieved a shift in fa- 
vour of tuber growth in potatoes. These triazoles inhibit the synthesis of gibberellic acid (Lürssen, 1988). Khazhakyan et al. (1979) found a delay of tuber initiation after applying GA to the stems of Jerusalem artichoke. Apparently, inhibition of GA synthesis in this experiment stimulated tuber initiation and led to a $59 \%$ higher tuber yield at final harvest.

The high total dry matter production of the transplanted crop (Table 3), can be attributed to the earlier emergence and rapid development in the greenhouse despite a clear inhibition of growth after transplanting in the field. The higher production of the crop treated with growth retardant is probably related to differences in losses. Early in October all crops were damaged by strong winds and lost some side branches. The losses were probably least in the somewhat shorter and sturdier plants treated with growth retardant.

The temporary storage of inulin in the stems means a certain risk of losses due to wind or early frost but has some metabolic costs too. Although the energetics of the fructan metabolism are not yet fully understood, the costs will amount 3-6 ATP per relocated molecule sucrose for the extra phloem loading and de-loading, the extra synthesis of sucrose from the monomers and possibly also for the transport to the vacuoles in the stem parenchym (Baker, 1985; Nelson \& Spollen, 1987; Pollock, 1986). These extra energy costs correspond to a 4-8\% loss of the stored carbohydrates. The costs of formation and maintenance of extra stem tissue could also be looked upon as losses from this temporary storage.

From the absence of the rapid relocation of inulin to the tubers with the vegetative long-day plants only, we infer that there is a direct link with the reproductive state. Incoll \& Neales (1970) suggested that short days directly affect relocation. In our experiment it is impossible to distinguish between the influence of short days as such and the effect via flower induction. After a short-day treatment Dickerson \& Edelman (1966) observed a shift in the flow of assimilates from the stems to the tubers and roots. Their results can also be interpreted as the short days having induced the reproductive phase, after which relocation is initiatied, causing the described 'photosynthate pressure' from the shoot to stolons and roots.

Until the 'pre-flowering' stage, Soja et al. (1989) found considerable polymerization activity in the stems. That activity disappeared in the subsequent period and then the assimilates moved directly to the tubers. Frehner et al. (1984) have shown that both the polymerizing and de-polymerizing enzyme systems occur in the vacuoles of the storage cells in tubers of Jerusalem artichoke. In the stems the activities of these opposing systems seem to be regulated by separation over time. That can explain the changes in relative sink strength of stems and tubers over the growth period. Until the reproductive phase the stems are the stronger sinks, probably because the polymerization maintains a steep sucrose gradient from the phloem to the stem parenchym. Downwards the sucrose concentration in the stem phloem drops and, in spite of a high polymerization capacity in the tubers (Soja et al., 1989), tuber filling proceeds at a slow rate. After flower initiation the stems lose their polymerizing activity (Soja et al., 1989) and become very weak sinks. Apparently, from then on the depolymerizing enzyme system is activated or becomes dominant, thereby triggering redistribution and rapid tuber filling. 
Our findings suggest that growers should aim at obtaining numerous tubers by encouraging crops to develop early, whereas breeders should search for genotypes that invest less in stem tissue and probably also for types that have little or no polymerizing activity in the stems.

\section{Acknowledgement}

We wish to thank Dr A. J. C. de Visser for his contribution to the discussion on the fructan metabolism.

\section{References}

Baker, D. A., 1985. Regulation of phloem loading. In: B. Jeffcoat, A. F. Hawkins \& A. D. Stead (Eds) Regulation of sources and sinks in crop plants, p. 163-176, Reading. Monograph 12, British Plant Growth Regulator Group.

Balamani, V. \& B. W. Poovaiah, 1985. Retardation of shoot growth and promotion of tuber growth of potato plants by paclobutrazol. American Potato Journal 62: 363-3689.

Barloy, J., 1988. Yield elaboration of Jerusalem artichoke. In: G. Grassi \& G. Gosse (Eds) Topinambour, p. 65-84. Report EUR 11855, Commission of the European Communities, Brussels.

Barloy, J. \& D. Poulain, 1988. Ecophysiological studies on Jerusalem artichoke and agricultural implications. In: J. Kisgeci \& U. Wuensche (Eds) Producing agricultural biomass for energy, p. 47-58. Proceedings of a FAO Conference at Uppsala, 1987. FAO, Rome.

Chabbert, N., Ph. Braun, J. P. Guirand, M. Arnoux \& P. Galzy, 1983. Productivity and fermentability of Jerusalem artichoke according to harvesting day. Biomass 3: 209-224.

Courduroux, J. C., 1967. Etude du mécanisme physiologique de la tuberisation chez le topinambour (Helianthus tuberosus L.). Annales des Sciences Naturelles, Botanique 12: 215-356.

Dickerson, A. G. \& J. Edelman, 1966. The metabolism of fructose polymers in plants. VI. Transfructosylation in living tissue of Helianthus tuberosus L. Journal of Experimental Botany 17: 612-619.

Frehner, M., F. Keller \& A. Wiemken, 1984. Localization of fructan metabolism in the vacuoles isolated from protoplasts of Jerusalem artichoke tubers (Helianthus tuberosus L.). Journal of Plant Physiology 116: $197-208$.

Hackbarth, J., 1937. Versuche über Photoperiodismus. IV. Über das Verhalten einiger Klone von Topinambur. Der Züchter 9: 113-118.

Hammer, K. C. \& F. L. Long, 1939/1940. Localization of photoperiodic perception in Helianthus tuberosus. Botanical Gazette 101: 81-90.

Incoll, L. D. \& T. F. Neales, 1970 . The stem as a temporary sink before tuberization in Helianthus tuberosus L. Journal of Experimental Botany 21: 469-476.

Jefferies, R. A. \& D. K. L. Mackerron, 1987. Thermal time as a non-destructive method of estimating tuber initiation in potatoes. Journal of Agricultural Science (Cambridge) 108: 249-252.

Khazhakyan, Kh. K., A. G. Devedzhyan \& M. Kh. Chailakhyan, 1979. Regulation of tuber formation in Jerusalem artichoke by means of physiologically active compounds. Doklady Akademii Nauk SSSR 248: 1021-1024.

Lürssen, K., 1988. Pflanzenphysiologische und biochemische Wirkungen des neuen Wachstumsregulators Triapenthenol (RSW 0411) (In German, with English summary). Pflanzenschutz-Nachrichten Bayer 41 (3) 299-331.

Nelson, C. J. \& W. G. Spollen, 1987. Fructans. Physiologia Plantarum 71: 512-516.

Pollock, C. J., 1986. Fructans and the metabolism of sucrose in vascular plants. The New Phytologist 104: $1-24$.

Soja, G., E. Haunold \& W. Praznik, 1989. Translocation of 14-C-assimilates in Jerusalem artichoke (Helianthus tuberosus L.). Journal of Plant Physiology 134: 218-223. 
Spitters, C. J. T., M. Lootsma \& R. van de Waart, 1988. The contrasting growth pattern of early and late varieties in Helianthus tuberosus. In: G. Grassi \& G. Gosse (Eds) Topinambour, p. 65-84. Report EUR 11855, Commission of the European Communities, Brussels.

Steinrücken, G., 1984. Research on the introduction of genetic variability in Helianthus tuberosus L. (In German). Thesis University of Hannover, $281 \mathrm{pp}$. 